\title{
Programa Mais Educação-Cachoeiro de Itapemirim, Espírito Santo, Brasil: desafios e possibilidades
}

\author{
Mais Educação (increased education) Program in Cachoeiro de Itapemirim, Espírito Santo, \\ Brasil: challenges and possibilities
}

Maria Deuceny da Silva Lopes Bravo Pinheiro, Alfredo Bravo Marques Pinheiro, António Gomes Ferreira. Doutoranda em Ciências da Educação da Faculdade de Psicologia e de Ciências da Educação da Universidade de Coimbra, bolsista da Capes/Programa Ciência sem Fronteiras; Doutorando em Ciências da Educação da Faculdade de Psicologia e de Ciências da Educação da Universidade de Coimbra, bolsista da Capes; Coordenador de Curso de Doutorado da Faculdade de Psicologia e de Ciências da Educação da Universidade de Coimbra, GRUPOEDE/CEIS20.

\section{Resumo}

Esta comunicação tem como objetivo realizar uma análise do Programa Mais Educação, criado em 2007, com base nos baixos índices de aprendizagem das escolas públicas brasileiras. Filiado ao plano de metas "Compromisso Todos pela Educação", tendo por base o conceito de educação integral e sua relação com o território como espaço de aprendizagem, o Programa apresenta uma proposta de jornada ampliada e organização curricular na perspectiva da Educação Integral, envolvendo a participação da família e da comunidade, através de parcerias e ampliação de tempos e espaços educativos.

Palavras-chave: Programa Mais Educação, Território Educativo, Sustentabilidade

\section{Abstract}

This document aims to perform an analysis of “Mais Educação” (Increased Education) program, implemented in 2007, based on the low indexes of learning in Brazilian public schools has enroll itself in the goals planning program called "”Compromisso Todos pela Educação" (All Engaged for Education),having for base the concept of integral education and its relation with the territory as a learning area. The program presents a proposal for an increased study time and for a curricular organization in perspective of full time Education, which implies family and community participation through partnership and increase of educational time and area.

Key words: "Mais Educação” Program,

Educational Territory, Sustainability.

\section{Introdução}

Procuramos nesta comunicação clarificar a evolução e a situação do Programa Mais Educação, pautadas no pressuposto que a abertura da escola à comunidade local, através do estabelecimento de parcerias com as instituições e organizações no território, fortalecem a relação de pertencimento, tornando esse território mais solidário, desenvolvido e sustentável.
Foram escolhidas, como estudo de caso, seis escolas que iniciaram o Programa Mais Educação no município de Cachoeiro de Itapemirim, ES, Brasil.

Os dados apresentados resultam da construção de um guião semi-estruturado utilizado nas entrevistas realizadas com os gestores, pedagogos, coordenadores e monitores dessas escolas.

Através das entrevistas, foi possível registrar os avanços e desafios enfrentados por aqueles atores na implementação do Programa Mais Educação e refletir sobre a importância e possibilidades de abertura da escola aos contextos locais, com ações criativas e integradas entre toda a comunidade escolar, através do compartilhamento de responsabilidade educativa entre famílias e poder público.

\section{O Programa Mais Educação}

Ao longo da história contemporânea do Brasil são encontrados vários registros de experiências diferenciadas de políticas públicas voltadas para a educação integral, com contributos significativos das Escolas-Parque concebidas por Anísio Teixeira na década de 1950 e os Centros Integrados de Educação Pública - CIEPs, no Estado do Rio de Janeiro, concebidos por Darcy Ribeiro, na década de 1980.

A partir da década de 1990 e ao longo deste início do século 21, presenciamos, em contexto mundial, experiências diferenciadas propondo atividades fora do espaço escolar através de parcerias para oferta de atividades complementares aos alunos, com metodologias diferentes e com a presença de outros agentes na construção de um território educativo (Coelho, 2012; Villar, 2007; Pereira, 2005; Ander-Egg, 2006).

Esse conceito, contemporâneo, ganhou força e expandiu-se a partir do movimento das Cidades Educadoras, em Barcelona, em 1990, com uma proposta de educação não mais só centrada na escola, mas pautada na formação do sujeito, contemplando as dimensões ética, social, cultural, cognitiva e política, articulando e dialogando com outros saberes, dentre eles, a comunidade, promovendo e fortalecendo os territórios educativos. 
Com uma proposta de jornada ampliada e organização curricular na perspectiva da Educação Integral, o Programa Mais Educação, criado em 2007, através da Portaria Interministerial $n^{\circ}$ 17/2007 e regulamentado pelo Decreto $\mathrm{n}^{0} 7.083 / 10$, com base nos baixos índices de aprendizagem das escolas públicas brasileiras, filia-se no plano de metas "Compromisso Todos pela Educação".

A Constituição Federal, artigos 205, 206 e 227, o Estatuto da Criança e do Adolescente - Lei $\mathrm{n}^{\circ}$ 9089/1990, a Lei de Diretrizes e Bases - Lei $n^{\circ}$ 9394/1996, artigos 34 e 87, o Plano Nacional de Educação - Lei 13.005/14, meta 6 e o Fundo Nacional de Manutenção e Desenvolvimento do Ensino Básico e de Valorização do Magistério-FUNDEB, Lei $n^{0}$ 11.494/2007 respaldam legalmente o Programa.

Com atividades optativas que, preferencialmente, devem ser trabalhadas de forma interdisciplinar, respeitando o contexto social do sujeito e ao processo de escolarização, prioriza as escolas que apresentam baixo Índice de Desenvolvimento da Educação BásicaIDEB; que se encontram em áreas de vulnerabilidade social; e que apresentam índices igual ou superior a $50 \%$ de estudantes cadastrados no Programa Bolsa Família (Manual Mais Educação, 2013).

Em seus fundamentos, o Programa pressupõe a aprendizagem conectada à vida e ao universo de interesses das crianças, dos adolescentes e dos jovens, reconhecendo as múltiplas dimensões do ser humano, com a possibilidade de formação integral da pessoa, envolvendo a participação da família e da comunidade na construção de uma agenda intersetorial entre as políticas públicas educacionais e sociais através de parcerias e ampliação de tempos e espaços educativos.

Nesse contexto, as escolas- na figura de seus gestores, professores, estudantes, funcionários e toda a comunidade escolar - são convidadas a refletir sobre o processo educacional como uma prática educativa vinculada com a própria vida e a contribuir com o processo de requalificar suas práticas.

Assim, os diversos atores escolares e sociais podem mobilizar estratégias de articulação, ressignificação e fortalecimento desta proposta, de modo que a própria cidade se constitua como espaço de formação humana (Moll, 2012), uma vez que o Programa aponta para uma tarefa educativa compartilhada entre a escola e os profissionais de outras áreas da conjuntura social, viabilizada por meio de práticas intersetoriais, incluindo também o apoio das famílias e agentes comunitários, no sentindo de, juntos, promoverem ações pedagógicas (BRASIL, 2009).

Percebe-se, na prática, que apesar dos avanços, dos estudos envolvendo o desempenho escolar dos estudantes que integram o Programa e das mudanças pedagógicas e curriculares, ocorre ainda, dentro das escolas, uma dificuldade de entendimento sobre a concepção e desenvolvimento de projetos e parcerias que promovam a educação integral e sua articulação com o meio social e cultural que caracteriza o contexto.

Essa realidade pode ser constatada ao analisarmos as seis primeiras escolas que iniciaram o Programa Mais Educação no município de Cachoeiro de Itapemirim,
Espírito Santo, Brasil, a partir do ano de 2009. Essas escolas, situadas em diferentes regiões geo-escolares da cidade, enfrentaram os desafios iniciais e serviram de parâmetro para as demais escolas em sua adesão.

Por se tratar de uma investigação de natureza essencialmente qualitativa, com ela pretende-se compreender tanto a singularidade da concretização do Programa Mais Educação em cada uma das escolas escolhidas, como compreendê-lo à luz dos seus princípios e das condições de um espaço maior, o território onde elas se localizam.

Os dados apresentados resultam da construção de um guião semi-estruturado utilizado nas entrevistas abertas, realizadas com os gestores, pedagogos, coordenadores e monitores dessas seis escolas.

Sendo exploratórias, as entrevistas foram guiadas pelo conhecimento que a investigadora já tem, a partir da revisão de literatura (Amado \& Ferreira, 2013; Marconi \& Lakatos, 2010; Coutinho, 2011), dos interesses e área de trabalho dos entrevistados, do conhecimento das suas perspectivas sobre a problemática da investigação e dos contributos dos entrevistados sobre outros projetos relevantes associados direta ou indiretamente no Programa Mais Educação.

Através dessas entrevistas, realizadas com o uso de gravador de voz portátil e posteriormente transcritas e literalizadas, foi possível verificar a percepção desses atores sobre os princípios norteadores do Programa Mais Educação e a dinâmica dos mesmos nas escolas consideradas, registrando as potencialidades e constrangimentos revelados e, assim, refletir sobre a importância e possibilidades de abertura da escola aos contextos locais, através do compartilhamento de responsabilidade educativa entre famílias e poder público.

A discussão sobre a proposta de Educação Integral não é simples e envolve muitas vezes, uma questão conceitual. Buscando verificar a percepção sobre os princípios norteadores do Programa e a concepção de Educação Integral adotada na rede municipal de ensino, o procedimento em todas as entrevistas foi iniciado com o auxílio de uma questão norteadora: "Qual a concepção de Educação Integral que vem sendo adotada pela Secretaria Municipal de Educação?"

A análise dos dados foi inspirada na análise de conteúdo (Amado, Costa e Crusoé, 2013), que consiste em articular os momentos de descrição, inferência e interpretação, implicando na apresentação da significação do conteúdo expresso pelos gestores, coordenadores, pedagogos e monitores entrevistados.

Os conteúdos das entrevistas, neste recorte, foram organizados em sistema de categorias, traduzindo as idéias-chave do discurso dos entrevistados e delineados nos seguintes núcleos: Percepção de Educação Integral, Percepção Geral do Programa Mais Educação e Mudanças Registradas com o Programa, sintetizadas em cada um dos quadros a seguir.

Quadro 1.

Percepção de Educação Integral

Tirar a criança com defasagem escolar da rua, ajudar mais sua socialização na escola. 


\begin{tabular}{l}
\hline $\begin{array}{l}\text { A educação da criança como um todo tanto na parte } \\
\text { cognitiva, esportiva, relacionamento social e formação do } \\
\text { ser como um todo. }\end{array}$ \\
\hline Trabalhar na formação do cidadão como um todo. \\
\hline $\begin{array}{l}\text { Oportunizar outras atividades que não sejam as disciplinas } \\
\text { convencionais. }\end{array}$ \\
\hline
\end{tabular}

Apesar de o Programa Mais Educação ser uma ação indutora da Educação Integral no Brasil, ainda há uma dificuldade em trabalhar com esses conceitos, uma vez que estão associados, na maioria das vezes, ao aumento da carga horária dos estudantes na escola; às atividades extracurriculares ofertadas (oficinas) e; como alternativa para minimizar a vulnerabilidade social desses estudantes.

A Escola, com o Programa Mais Educação, muda a sua rotina. A permanência dos estudantes durante sete horas diárias, para o desenvolvimento de atividades curriculares e extracurriculares tem exigido mudanças pedagógicas e administrativas que vêm sendo, gradativamente, percebidas pelos entrevistados ao serem indagados sobre o que mudou com o Programa Mais Educação.

Quadro 2

Mudanças Registradas

\begin{tabular}{|l|l|}
\hline \multirow{5}{*}{ Administrativas } & $\begin{array}{l}\text { Mudança de visão e confiança no } \\
\text { Programa por parte da Gestão } \\
\text { Escolar e da Gestão Pública. }\end{array}$ \\
\cline { 2 - 3 } & $\begin{array}{l}\text { Curso de Formação para equipe que } \\
\text { trabalha com o Programa. }\end{array}$ \\
\cline { 2 - 2 } & $\begin{array}{l}\text { Apoio Técnico-pedagógico para as } \\
\text { escolas. }\end{array}$ \\
\cline { 2 - 2 } & $\begin{array}{l}\text { Apoio na divulgação e exposição das } \\
\text { oficinas, com apresentação no Teatro } \\
\text { e exposição de fotografias. }\end{array}$ \\
\hline Pedagógicas & Melhoria no rendimento escolar. \\
\cline { 2 - 2 } & $\begin{array}{l}\text { Planejamento integrado com monitor } \\
\text { e pedagogo. }\end{array}$ \\
\cline { 2 - 2 } & $\begin{array}{l}\text { Mudança de comportamento e de } \\
\text { postura dos alunos. }\end{array}$ \\
\hline
\end{tabular}

Aprender mais, desenvolver a capacidade de relacionamento e de trabalho em grupo e a relação de pertencimento dos estudantes com a escola foram potencialidades presentes registradas nos relatos dos entrevistados.

Quadro 3

Percepção Geral do Programa

\begin{tabular}{|l|l|}
\hline \multirow{5}{*}{ Fragilidades } & $\begin{array}{l}\text { A escola ter que educar os pais para } \\
\text { manterem os alunos na escola. }\end{array}$ \\
\cline { 2 - 2 } & $\begin{array}{l}\text { Faltam parceiros e as atividades são } \\
\text { acontecem dentro da escola. }\end{array}$ \\
\cline { 2 - 2 } & $\begin{array}{l}\text { A estrutura física das escolas que } \\
\text { temos hoje não suporta a ampliação } \\
\text { da jornada escolar. }\end{array}$ \\
\cline { 2 - 2 } & $\begin{array}{l}\text { Não é seguro sair da escola para } \\
\text { realização das oficinas. }\end{array}$ \\
\cline { 2 - 2 } & $\begin{array}{l}\text { A dificuldade que tivemos foi com o } \\
\text { monitor }\end{array}$ \\
\hline & $\begin{array}{l}\text { A escola tornou-se mais rica com } \\
\text { relação ao material didático. }\end{array}$ \\
\cline { 2 - 2 } & $\begin{array}{l}\text { Houve melhora na aprendizagem e } \\
\text { no desempenho escolar. }\end{array}$ \\
\hline
\end{tabular}

\begin{tabular}{|c|c|}
\hline \multirow[t]{2}{*}{ Potencialidades } & $\begin{array}{l}\text { Além de mudança no planejamento, } \\
\text { mudou o objetivo da escola. }\end{array}$ \\
\hline & $\begin{array}{l}\text { A grande contribuição do Programa é } \\
\text { a autoestima dos alunos, } \\
\text { principalmente quando fazem uma } \\
\text { apresentação em outros espaços, fora } \\
\text { da escola. A escola também ganha } \\
\text { visibilidade na sociedade com as } \\
\text { apresentações do Programa. }\end{array}$ \\
\hline \multirow{2}{*}{ Potencialidades } & $\begin{array}{l}\text { Mudança de visão da comunidade } \\
\text { escolar com relação aos alunos que } \\
\text { estão no programa e do programa } \\
\text { também em si, quando as atividades } \\
\text { são divulgadas. }\end{array}$ \\
\hline & $\begin{array}{l}\text { Hoje, diferente da resistência inicial, } \\
\text { a comunidade escolar aceita muito } \\
\text { bem o programa. }\end{array}$ \\
\hline \multirow{3}{*}{ Desafios } & $\begin{array}{l}\text { Incluir o Programa no Plano de } \\
\text { governo. Instituir uma política } \\
\text { pública de educação integral. }\end{array}$ \\
\hline & $\begin{array}{l}\text { Investir mais no espaço físico, na } \\
\text { infra-estrutura das escolas. }\end{array}$ \\
\hline & $\begin{array}{l}\text { Divulgar mais o Programa e mostrar } \\
\text { aos pais e à comunidade/sociedade } \\
\text { como esses alunos são talentosos e o } \\
\text { que são capazes de fazer. }\end{array}$ \\
\hline
\end{tabular}

O financiamento e a contratação de monitores para o desenvolvimento das oficinas foram os principais desafios apresentados.

Nesse contexto, podemos destacar a importância da institucionalização de uma política pública para a construção da educação integral que supere a dicotomia turno x contraturno, que articule e promova a interação da escola com a comunidade superando as fragilidades diagnosticadas.

Percebe-se que a escola continua centralizadora de todas as atividades curriculares e extracurriculares no desenvolvimento do Programa Mais Educação, inibindo a articulação escola-território.

\section{Território Educativo}

Embora a escola tenha sido criada para sistematizar o conhecimento formal do indivíduo, a formação do mesmo também está inserida em outros espaços sociais (Trilla,1999;Villar, 2007; Ander-Egg, 2006).

Ao ultrapassar os muros da escola, estamos permitindo que a cidade se transforme em um território de aprendizagem e de construção da cidadania e a escola, uma entre as muitas instituições da sociedade que promovem a educação.

Educar é mais que passar informação, é desenvolver a pessoa e contribuir para uma melhor relação dela com o mundo que a rodeia; é explorar o território e suas possibilidades; é exercitar a democracia e estimular a criatividade na construção de uma sociedade mais participativa e mais autônoma.

Uma escola conectada ao território- entendido como o espaço de trocas materiais e espirituais e do exercício da vida- possibilita um diálogo permanente e renovado com o espaço vivido (Santos, 2006), aproximando educador e educando no processo de construção do conhecimento. 
Enquanto instituição educativa, a escola tem, na sua essência, a missão de educar para cidadania. Se ao longo da história essa missão esteve presente nos sistemas educativos, nas últimas décadas, o conceito de cidadania engloba a dimensão ética da responsabilidade, no sentido em que privilegia tanto o ser para si mesmo como o ser para com os outros.

A cidade, por sua vez, além de recurso pedagógico das escolas, possui possibilidades educativas capazes de motivar e sensibilizar o cidadão em defesa da qualidade de vida (Villar, 2007; Pereira, 2005).

Na prática, foi possível identificar, através das entrevistas realizadas, que o compartilhamento da responsabilidade educativa entre famílias e poder público para além da escola, com ações criativas e integradas entre toda a comunidade escolar ainda é restrito.

A execução do Programa Mais Educação, responsabilidade dos coordenadores em cada escola, acaba não integrando, muitas vezes, toda a equipe escolar, limitando parcerias e a reflexão sobre a importância do território na promoção e criação de recursos necessários que amplie a dimensão educativa.

Os relatos registrados nas entrevistas revelam essa limitação e a necessidade de adequação do Projeto Pedagógico à diversidade e especificidade dos territórios.

Quadro 4

Relação Escola-Comunidade

\begin{tabular}{|c|}
\hline Parcerias \\
\hline $\begin{array}{l}\text { Faltam parceiros e as atividades não acontecem } \\
\text { dentro da escola. }\end{array}$ \\
\hline $\begin{array}{l}\text { Temos grande dificuldade no acompanhamento } \\
\text { familiar. }\end{array}$ \\
\hline $\begin{array}{l}\text { O programa realmente está muito conhecido e } \\
\text { quando vamos buscar parceria alguns nos negam } \\
\text { por saberem que recebemos uma verba específica } \\
\text { só para o Programa Mais Educação. }\end{array}$ \\
\hline $\begin{array}{l}\text { Não temos parceiros. Todas as atividades se } \\
\text { desenvolvem dentro da escola. }\end{array}$ \\
\hline $\begin{array}{l}\text { Nós não procuramos parceiro e o único parceiro } \\
\text { que tivemos foi no Clube de Judô com o monitor. }\end{array}$ \\
\hline Nossa parceria é com a Secretaria de Educação. \\
\hline Temos dificuldades em contratar monitores. \\
\hline
\end{tabular}

A maior parte das escolas que desenvolvem o Programa Mais Educação esta localizada em área de vulnerabilidade social, com estrutura precária, o que dificulta as parcerias.

Constata-se a necessidade de investimento em mudanças no interior das unidades escolares, de forma a compatibilizar a presença de alunos e professores em turno integral, ao mesmo tempo, registra-se, também, a necessidade de articular instituições e projetos junto à comunidade de forma a aproximar parceiros.

Ao interagir família-escola-comunidade, estamos ampliando as oportunidades e os potenciais educativos envolvidos no processo de aprendizagem. É preciso vencer esse desafio.

\section{Considerações Finais}

A educação integral não é obra apenas da escola. Ela faz parte de um conjunto de ações que exige uma política local de educação que dialogue com a escola e valorize o território como possibilidade de espaço educativo, compartilhando saberes e responsabilidade educativa entre famílias e poder público, fortalecendo assim a convivência comunitária na construção de um território sustentável e do bem-estar comum.

Integrar e articular os potenciais educativos das comunidades (espaços, pessoas, instituições e iniciativas); garantir condições para o desenvolvimento integral e o empoderamento de sujeitos de direito das comunidades; possibilitar o envolvimento e a percepção de todos como agentes transformadores da sociedade de seu tempo, co-responsáveis pelo processo educativo num território sustentável tem sido o grande desafio da educação integral e do Programa Mais Educação.

\section{Referências}

Ander-Egg, E. (2006). La ciudad educadora como forma de fortalecimento de la democracia y una ciudadania activa y convivencial. 1.ed. Códoba: Brujas.

Amado, J, Costa, A. P e Crusoé, N. (2013). A técnica de análise de conteúdo. In J. Amado (Coord.). Manual de investigação qualitativa em Educação (pp. 201-350). Coimbra: Imprensa da Universidade de Coimbra.

Amado, J. e Ferreira, S. (2013). A entrevista na investigação educacional. In J. Amado (Coord.). Manual de investigação qualitativa em educação (pp. 207-290). Coimbra: Imprensa da Universidade de Coimbra.

Brasil. Portaria Normativa Interministerial Nº-17, de 24 de Abril de 2007.Institui o Programa Mais Educação, que visa fomentar a educação integral de crianças, adolescentes e jovens, por meio do apoio a atividadessócio-educativas no contraturnoescolar. Disponível http://portal.mec.gov.br/index.php?option=com_doc man\&task=doc_download\&gid=2446\&Itemid=

Brasil. Decreto n ${ }^{\circ}$ 7.083, de 27 de janeiro de 2010. Dispõe sobre o programa mais educação. Disponívelhttp://www.planalto.gov.br/ccivil_03/_ato 2007-2010/2010/decreto/d7083.ht

Brasil. Resolução CD/FNDE N. 18 de 21 de maio de 2013. Dispõe sobre a destinação de recursos financeiros, nos moldes operacionais e regulamentares do Programa Dinheiro Direto na Escola (PDDE), a escolas públicas municipais, estaduais e distritais que possuam alunos matriculados na educação básica, de acordo com dados extraídos do Censo Escolar do ano imediatamente anterior ao do repasse, a fim de favorecer a melhoria da qualidade de ensino e a promoção da sustentabilidade sócio ambiental nas unidades escolares. Disponível em: $<$ http://www.fnde.gov.br/fnde/legislacao/resolucoes/i tem/4542-resolu\%C3\%A7\%C3\%A3o-cd-fnde- 
n\%C2\%BA-18,-de-21-de-maio-de-2013>

Brasil. Lei $\mathrm{n}^{\circ}$ 9.394, de 20 de dezembro de 1996. Estabelece as diretrizes e bases da educação nacional. Disponível em http://www.planalto.gov.br/ccivil_03/leis/19394.htm

Santos, Milton (2006). Por uma outra globalizaçãodo pensamento único à consciência universal. Rio de Janeiro: Record.

Cordeiro, A. M.R; Alcoforado, L. e Ferreira, A. G.(2011/12). Projeto Educativo Local. Um processo associado a estratégias de desenvolvimento integrado e sustentável. Cadernos de Geografia, Coimbra, FLUC - 30/31, pp. 305-315.

Coutinho, C. P. (2011). Metodologia de investigação em Ciências Sociais e Humanas. Coimbra: Almedina.

Gomez, J. A. C.; Freitas, M. O e Callejas (2007). Educação e desenvolvimento comunitário local : perspectivas pedagógicas e sociais da sustentabilidade. $\quad$ Porto:
Gómez-Granell, C; e al. (2001). La ciudad como proyecto educativo. Barcelona.Octaedro.

Marconi, M. A e Lakatos, E. M.(2010). Técnicas de

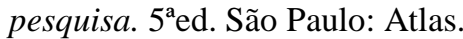

Moll, J. (2012). A agenda da educação integral: compromissos para sua consolidação como política pública. In: Moll, J. e colaboradores. Caminhos da educação integral no Brasil: direito a outros espaços tempos e espaços educativos. Porto Alegre: Penso Editora Ltda.

Manual Operacional de Educação Integral(2013). Brasília/DF. Ministério da Educação Secretaria de Educação Básica. Diretoria de Currículos e Educação Integral.

Pereira, Sofia (2005). Á procura da cidade educadora: a organização do espaço e dos recursos na promoção da cidadania em Leiria. Universidade da Beira Interior. Portugal. Dissertação de Mestrado.

Trilla Bernet, J. (1993). Otras educaciones. Animación sociocultural, formación de adultosy ciudad educativa. Barcelona, Anthropos. 